\title{
Historiografía cubana. Entrevista a Óscar Zanetti Lecuona
}

\section{Cuban Historiography. Interview with Oscar Zanetti Lecuona}

\author{
Martín Lara* \\ Universidad Católica Silva Henríquez
}

\section{Resumen}

Entrevista realizada al historiador Óscar Zanetti, profesor de la Universidad de La Habana. En la conversación transcrita se pasa revista a su formación, principales investigaciones y diversos tópicos concernientes a la historiografía cubana del siglo XX, como la profesionalización de la disciplina, tendencias temáticas durante la Guerra Fría, influencias y actuales desafíos académicos en vista de la reciente reanudación de las relaciones diplomáticas entre Washington y La Habana.

Palabras clave: historiografía, Cuba, exilio, historia social, Guerra Fría

* Profesor en dicha casa de estudios y en la Universidad Nacional Andrés Bello. Sus áreas de interés son la historia de la historiografía, historia cultural e historia social de Chile y América en los siglos XIX y XX. A coeditado Historias de racismo y discriminación en Chile (2009).

Contacto: martinlara@uc.cl 


\begin{abstract}
Interview with historian Óscar Zanetti, professor at the Universidad de La Habana. The interview reviews his academic development and main research topics. It focuses on several subjects concerning $20^{\text {th }}$ century Cuban historiography, such as the professionalization of the discipline, lines of research during the Cold War, influences, and current academic challenges in light of the restoration of diplomatic relations between Washington and La Habana.
\end{abstract}

Key words: historiography, Cuba, exile, social history, Cold War

$$
* * *
$$

En el transcurso de enero del 2015 en la ciudad de La Habana, tuve la oportunidad de reunirme con el Dr. Óscar Zanetti Lecuona, uno de los historiadores cubanos más respetados dentro y fuera de su país. Gran parte de su carrera la desarrolló al alero del Departamento de Historia de la Universidad de La Habana, al cual se incorporó en 1963 como estudiante. Siguiendo el cursus honorum logró escalar cada uno de los peldaños de la carrera académica, convirtiéndose en ayudante de cátedra (1963), instructor (1964), profesor (1965), jefe de departamento (1965-1987) y miembro del Comité Científico de la universidad, en la que actualmente continúa trabajando como profesor titular a tiempo parcial en el Programa de Doctorado. En el 2011, en reconocimiento a la obra de toda una vida, se le concedió el Premio Nacional de Ciencias Sociales y Humanísticas; y recientemente, se le otorgó el Premio Nacional de Historia versión 2014. Hoy su mayor actividad profesional la desarrolla como Académico de número de la Academia de la Historia de Cuba. 
Sus investigaciones publicadas han girado en torno a la historia económica de Cuba y sus dimensiones políticas y sociales. La singularidad de los estudios del profesor Zanetti radica no solo en la rigurosidad científica de sus aproximaciones, sino que sus apreciaciones, en general, se han caracterizado por una imparcialidad política sin influencia del espíritu castrista de la época en la cual desarrolló su carrera.

La conversación, que originalmente trató sobre mi lectura de su último libro Auge y caída de la industria azucarera en las Antillas hispanas, desembocó en una serie de temas que bien vinculadas, daban espacio para reconocer el desarrollo historiográfico cubano desde 1950 hasta principios del siglo XXI. La importancia de entender las características de la historiografía cubana de los últimos cincuenta años, de manos de uno de sus más insignes representantes, permitirá comprender en mejor medida las posibles consecuencias del acercamiento diplomático entre Cuba y Estados Unidos con el restablecimiento de las relaciones diplomáticas, lo que sin duda en un mediano plazo modificará supuestos o, en el mejor de los casos, generará tensiones en el actual paradigma del desarrollo historiográfico de la isla caribeña.

De lo anterior, surge la siguiente entrevista que se desarrolló entre Cuba, España y Chile.

\section{1. ¿Por qué decidió estudiar historia?}

La historia era una afición familiar, tanto de mi padre como de mi abuelo materno. Ellos me regalaban novelas de aventuras -Alejandro Dumas, Emilio Salgari, Julio Verne, etc.-, muchas con un fondo histórico que me abrían interrogantes que mi padre y mi abuelo me explicaban, además de incitarme a averiguar por mí mismo en los libros de historia. Poco a poco, me fui dando cuenta de que la historia misma podía resultar tanto o más cautivadora que la ficción. 
2. De sus primeras lecturas, ¿qué libros fueron influyentes en la etapa inicial de su formación? ¿A qué maestros o profesores debe parte de su interés por la historia económica?

De las lecturas históricas cubanas, algunas obras clásicas fueron Historia de Cuba de Fernando Portuondo y el Manual de bistoria de Cuba de Ramiro Guerra. También algunas memorias y testimonios de nuestras guerras de independencia, al estilo del libro del general Manuel Piedra Martel Memorias de un Mambi o los Episodios de la Revolución cubana de Manuel de la Cruz. Claro que se trata de referencias que dirán muy poco a lectores no cubanos.

Respecto a la historia universal, creo que una de mis primeras lecturas fue una colección de pequeños y viejos textos de historia universal de Albert Malet que había en casa. La clásica Historia de la Revolución francesa de Albert Mathiez y algunas biografías -el infaltable Napoleón de Georges Lefebvre y otros más-; mayor impresión en un sentido profesional me causaron textos como la Apología de la historia de Marc Bloch, El 18 de brumario de Luis Bonaparte de Karl Marx o Stalin: Una biografía politica de Isaac Deustcher.

Ninguno de los historiadores cubanos más renombrados de mediados del siglo XX fue directamente mi profesor de aula, pero algunos de ellos ejercieron cierta influencia en mi formación. Ante todo está Juan Pérez de la Riva, con quien tuve el privilegio de trabajar directamente, pues lo sustituí en la asignatura que impartía en la Universidad de La Habana; también Manuel Moreno Fraginals, por su estilo e inquietudes; así como Julio Le Riverend y Oscar Pino Santos por afinidades temáticas.

3. ¿Cómo recuerda la enseñanza de la historia y la formación de historiadores en la Universidad de La Habana a inicios de la década de 1960? 
La historia no existía en Cuba como carrera universitaria, era - unida a la geografía- una especialidad de la Facultad de Filosofía y Letras. La licenciatura en historia se creó con la reforma universitaria de 1962. Como te imaginarás, casi ninguno de sus profesores era historiador con formación profesional, salvo Carlos Funtanellas que impartía Historiografía y había hecho una maestría en el Colegio de México. El resto eran profesores provenientes de la enseñanza de bachillerato, periodistas y diplomáticos; aunque teníamos una figura tan relevante como Alejo Carpentier, que durante un par de años impartió Historia de la Cultura. El grueso de las materias eran informativas como Prehistoria, Historia Medieval, Historia de Cuba, América, etc., con algunas disciplinas teóricas -Filosofía, Economía Política- y una sola asignatura de tipo instrumental: Técnicas de la Investigación Histórica, que impartía con gran amor Hortensia Pichardo. Ella fue quien primero nos llevó a un archivo y puso documentos en nuestras manos; había sido profesora de enseñanza media con una formación investigativa autodidacta en lo que hoy llamamos el paradigma documental-positivista y utilizaba a Charles Langlois y Charles Víctor Seignobos, Zacarías García Villada y Wilhelm Bauer como bibliografía.

4. ¿La metodología y principios teóricos de la historiografía cubana durante la primera mitad del siglo XX en qué grado fue influenciada por su símil estadounidense?

Por la cercanía cultural, económica y política, la obra de los principales historiadores norteamericanos de la época era conocida y leída por sus colegas cubanos. Es más difícil precisar influencias, aunque la de Charles Beard me parece bastante clara en el caso de Ramiro Guerra; otros historiadores como Allan Nevins o French Ensor Chadwick sin duda fueron consultados por el propio Guerra y por Herminio Portell Vilá, quien escribió una monumental obra en 4 tomos sobre la historia de las relaciones cubano-norteamericanas 
titulada Historia de Cuba en sus relaciones con los Estados Unidos y España. Autores como Scott Nearing o Leland Jenks, que trataban el fenómeno imperialista, estaban presentes en las lecturas de la intelectualidad cubana de la época y también entre los historiadores, particularmente en la obra de Emilio Roig de Leuchsenring. Un caso particular es el de Fernando Ortiz, básicamente un antropólogo, pero con relevantes aportes historiográficos, en quien resulta perceptible la influencia de autores como Bronislaw Malinowski, de origen polaco pero que desarrolla su carrera en Gran Bretaña y EE. UU., o Franz Boas.

5. ¿Cambió de alguna manera el enfoque de hacer historia en Cuba tras la revolución de 1959? ¿Hubo una revolución en la historiografía o el cambio fue más bien paulatino?

Las dos tendencias básicas que conforman la historiografía revolucionaria existían desde antes. Una, el nacionalismo, era en realidad una tradición tan antigua como la historiografía misma, pues ya con el regidor José Martín Félix de Arrate - uno de nuestros primeros historiadores- se aprecia ese orgullo patriótico de la historiografía nacionalista, aunque entonces fuese todavía de la patria chica, habanera. Durante la prolongada gesta independentista contra España, esta tendencia devino central en nuestra creación historiográfica. Ya en el siglo XX, con la intervención y posterior injerencia norteamericana, el nacionalismo se radicaliza y alcanza incluso expresiones antiimperialistas en autores como el ya mencionado Roig de Leuchsenring. A Roig, la revolución le llega en la etapa final de su vida, pero en esos breves años y por su obra anterior hizo una contribución muy notable al nuevo discurso histórico.

La otra corriente, el marxismo, era mucho más reciente pues aunque puede mencionarse algún antecedente, cobra una presencia definida a finales de la década de 1930 y princi- 
pios de los cuarenta. Sus primeros exponentes fueron intelectuales y profesores que militaban en el Partido Comunista -Sergio Aguirre y Jorge Castellanos, por ejemplo- y algún dirigente de este como Carlos Rafael Rodríguez, aunque también tuvo manifestaciones no vinculadas a ese partido. Tal es el caso de Raúl Cepero Bonilla, un abogado y periodista de fuerte vocación y talento historiográficos, que en alguna medida expresa la variante cubana del revisionismo histórico de inspiración marxista que a finales de los cuarenta florece en otros países latinoamericanos. Cepero fue ministro de Comercio del Gobierno Revolucionario y murió en un accidente aéreo en 1962 siendo presidente del Banco Nacional. También el influjo marxista es perceptible en los primeros historiadores con formación profesional -Julio Le Riverend y Manuel Moreno Fraginals en el Colegio de México, Juan Pérez de la Riva en Francia- quienes paradójicamente al triunfar la revolución, aún no habían podido ejercer profesionalmente como historiadores.

Ese será el núcleo de la historiografía de la revolución que, sin embargo, en sus primeros pasos tiene un desempeño muy pragmático, encaminado a la formación de la conciencia revolucionaria de la población y a la reformulación del discurso tradicional sobre las nuevas bases ideológicas. En lo relativo al marxismo, asimilado pobremente y a la carrera en manuales soviéticos, ello daría lugar a textos harto esquemáticos de finalidad más que todo docente. La cristalización de una historiografía revolucionaria de carácter creativo tomaría todavía algunos años y su aparición puede datarse con la publicación del primer tomo de El Ingenio, complejo socioeconómico cubano de Moreno Fraginals, en 1964, y la emergencia de una nueva generación de historiadores como Jorge Ibarra y José Tabares del Real a finales de esa misma década.

6. ¿De alguna forma la historiografía cubana se vio influenciada por la historiografía soviética? 
La influencia soviética sobre el quehacer historiográfico en Cuba se verificó primero mediante textos teóricos, manuales que explicaban el materialismo histórico, la dialéctica y sus leyes, así como los principios de la economía política. Ellos influyeron en las aplicaciones del concepto de modo de producción en su versión estalinista, lo cual dio lugar a algún que otro disparate, pues esa conceptualización esquemática se avenía poco con nuestra realidad histórica.

En los años sesenta, los libros soviéticos propiamente históricos que circulaban en Cuba eran pocos, algunos de ellos como los de Evgueni Tarle sobre la Francia revolucionaria eran publicados por la Editorial Futuro, creo que en Argentina. Junto con estos circulaban las obras de historiadores marxistas occidentales como Gordon Childe y de autores que, sin ser marxistas, presentaban una versión novedosa de la historia, como el citado Bloch y Edward H. Carr, cuyas pequeñas obras de carácter metodológico fueron editadas en Cuba en esos años.

La situación cambió en la década de 1970 tras el fracaso de la zafra de los 10 millones, concebida como el pivote económico de lo que - usando un término de la época- pretendió ser la vía cubana al socialismo. Cerrada esa etapa experimental, la revolución se ajustó a los moldes del socialismo real en lo económico y lo político, proceso que tuvo su consecuencia cultural en el llamado quinquenio gris, una etapa de dogmatismo y cerrazón que en las ciencias sociales resultó bastante más prolongada. Pero incluso en esos años, la presencia de la historiografía soviética en Cuba fue relativamente escasa; seguían influyendo más los esquemas teóricos y, en el plano histórico, los enfoques institucionales centrados en lo partidista y el movimiento obrero, a veces importados por profesores soviéticos o colegas que hicieron sus doctorados en ese país. Pese a todo, esa oleada no pudo sepultar la tradición historiográfica nacionalista, ni torcer la interpretación de 
procesos que, como la propia revolución - que no había sido hecha por un partido comunista-, se adaptaban mal a tales esquemas. Más bien, lo que se sufrió fue una ideologización en la interpretación de los procesos históricos, una tendencia a esquematizar la historia nacional con finalidades políticas, cuya secuela se deja sentir todavía.

\section{7. ¿Se puede hablar de una historiografía del exilio?}

Tras el triunfo de la revolución, un buen número de historiadores académicos - comenzando por el propio presidente de la Academia de la Historia, Emeterio Santovenia- abandonaron el país y algunos pudieron continuar su obra en el exilio. A mi juicio, el más destacado de esos historiadores que salieron de Cuba ya formados fue Levi Marrero, que con gran perseverancia y admirable dedicación publicó una obra monumental en 15 volúmenes, que abarca la mayor parte del período colonial, cuyo formato y formulaciones marcan cierta distancia con la historiografía más tradicional. Sin embargo, la producción de esos historiadores profesionales - entre los cuales pueden mencionarse otros como Luis Aguilar o Rafael Fermoselle--, no constituye el mainstream de lo que podría calificarse como una historiografía del exilio. Este puede encontrarse principalmente en la nutrida y variopinta serie de publicaciones de la Editorial Universal de Miami, que incluye obras cuasi testimoniales sobre la historia reciente por protagonistas más o menos relevantes del acontecer vinculado a la Revolución cubana, así como otras quizás más cuantiosas pero de muy diversa valía que tratan temas tradicionales de nuestra historia, como las guerras de independencia.

Mención aparte debe hacerse de una nueva generación de historiadores de origen cubano formados en universidades norteamericanas, que con notable profesionalismo investigan problemas de nuestra historia y han dado a la luz obras 
en las que se produce una peculiar confluencia de ciertas tradiciones historiográficas cubanas y el habitus académico norteamericano. Otro grupo, aún más reciente, está integrado por historiadores formados en Cuba durante las décadas de 1980 y 1990 que han realizado su obra en extranjero -no solo en Estados Unidos, sino en España, México y otros países-, pero cuyas publicaciones mantienen bastante cercanía con el modo de hacer en la isla.

8. ¿Qué diferencias y similitudes se pueden establecer entre la historiografía cubana insular y la del exilio?

Esto constituye un problema tan interesante como carente de estudio. En realidad, dada la variedad de la creación historiográfica de uno y otro lado, resultaría muy aventurada cualquier generalización, que es lo único que podría plasmarse en tan breves líneas. Desde luego, hay coincidencias temáticas y discrepancias de enfoque, y hasta de terminología. Lamentablemente, todavía son frecuentes las descalificaciones que provienen de todas partes y ello dificulta el diálogo, una práctica indispensable para que florezca una producción historiográfica, que siendo común por sus asuntos será inevitablemente diversa y polémica en sus interpretaciones.

8. ¿Cuáles son las actuales características temáticas y enfoques de la historiografía cubana?

Continúan teniendo un notable peso los trabajos sobre el 210 proceso independentista, aunque se ha acrecentado la investigación sobre el llamado período republicano que se extiende entre 1900 y 1959. Respecto a la Revolución, período en el cual han predominado ampliamente los trabajos sobre la lucha contra la dictadura de Batista, van plasmándose algunos resultados destacables sobre procesos más recientes, particularmente los de carácter cultural. 
Desde el punto de vista de los enfoques, es apreciable el desarrollo de una historiografía sociocultural, a tono con las tendencias universales, por parte de colegas más jóvenes; cierta decadencia de la historia económica - que fue el "ábrete sésamo" de mi generación- y sobre todo una diversificación de métodos y perspectivas analíticas, incluso en el acercamiento a temas tradicionales, que abarca desde la microhistoria y el enfoque de género, hasta la historia intelectual. También ha cobrado fuerza la historia regional y local, resultado de la ampliación territorial de la enseñanza superior y del vigor de la actividad cultural e historiográfica en distintas ciudades del país.

9. ¿Cuáles serán los desafíos de la historiografía cubana en los próximos años?

No muy diferentes de los desafíos que enfrenta el país. En primer término, el de insertarse en el movimiento historiográfico mundial asimilando conceptos, métodos y técnicas de trabajo actuales, sin por ello perder de vista la especificidad de nuestros problemas históricos. En el análisis de estos, adquirir una perspectiva que permita superar las apreciaciones -a menudo estrechas- del enfoque histórico nacional, conservando, sin embargo, ese preciado bien que es la identidad. $\mathrm{Y}$ por último, aunque no menos importante, convertirse en un genuino espacio de debate, abierto a disímiles interpretaciones en un marco de respeto y con un criterio más relativo en materia de verdades.

\section{Libros de Óscar Zanetti Lecuona:}

- La escritura del tiempo. Historia e historiadores en Cuba contemporánea. La Habana: Ediciones Unión, 2015. En prensa. 
- Historia minima de Cuba. México: Taurus, 2013.

- Esplendor y decadencia del azúcar en las Antillas hispanas. La Habana: Ruth Casa editorial y Editorial de Ciencias Sociales, 2012.

- Manuel Moreno Fraginals (La Habana: Órbita y Ediciones Unión, 2009.

- Economía azucarera cubana. Estudios históricos. La Habana: Editorial Ciencias Sociales, 2009.

- La República: Notas sobre economía y sociedad. La Habana: Editorial Ciencias Sociales, 2006.

- Isla en la Historia. La bistoriografía de Cuba en el siglo XX. La Habana: Editorial Unión, 2005.

- Las manos en el dulce. Estado e intereses en la regulación de la industria azucarera cubana. La Habana: Editorial Ciencias Sociales, 2004.

- Comercio y poder. Relaciones cubano-hispano-norteamericanas en torno a 1898. La Habana: Casa de las Américas, 1998.

- Dinámica del estancamiento. El cambio tecnológico en la industria azucarera cubana entre 1926 y 1959. La Habana: Instituto de Historia de Cuba, 1996.

212 - Los cautivos de la reciprocidad. La Habana: ENSPES, 1989.

- Caminos para el azúcar. Coautor con Alejandro García. La Habana: Editorial Ciencias Sociales, 1987.

- Metodología de la investigación histórica. Coautor. La Habana: Editorial Pueblo y Educación, 1985. 
- El proceso de la investigación histórica. La Habana: ENSPES, 1979.

- United Fruit Co.; Un caso del dominio imperialista en Cuba. La Habana: Editorial Ciencias Sociales, 1976.

Recibido: 05 de agosto del 2015

Aceptado: 26 de noviembre del 2015 